\title{
The Rule/Principle of No Loss at Perspective of Five Religions
}

\author{
Hamed Mostaeed Hesari ${ }^{1} \&$ Javad Vahedi Zadeh ${ }^{1}$ \\ ${ }^{1}$ Department of Islamic law and jurisprudence, Ardabil Branch, Islamic Azad University, Ardabil, Iran \\ Correspondence: Javad Vahedi Zadeh, Department of Islamic law and jurisprudence, Ardabil Branch, Islamic \\ Azad University, Ardabil, Iran.
}

Received: March 5, 2016 Accepted: March 27, 2016 Online Published: March 31, 2016

doi:10.5539/jpl.v9n2p254 URL: http://dx.doi.org/10.5539/jpl.v9n2p254

\begin{abstract}
The present study examines juridical aspects of principle of no loss. The major basis of this principle is justice. Perhaps because of this reason, "principle of no loss" has priority over the rest of arguments like private and public and etc. Or it has control over generality and universality and applicability of arguments. And here, the view of jurists and lawyers is different at giving right prejudicial or give it to the injured party. This is the assumption that has been considered in most verses and hadith evidence of the principle of no loss. This indicates that "the idea of changing circumstance" before known in European rights, it had known at the rights of Islamic law centuries ago. Regarding to the views of Sunni religious leaders and scholars after them-it is clear that Sunni jurisprudence has no clear criteria for principle of no loss. Although, in many cases, Sunni religious leaders have considered the nature of the harm, but because in practice the current principle could not solve all of the issues and problems, therefore, they have resort other criteria and finally they resort to preference and correction.
\end{abstract}

\section{Introduction}

One of the most famous juridical rules that most of field of law such as worship, transactions, etc. can be cited to that, is the "no loss" rules that are able do many of these juridical issues. The importance of mentioned rule is at the extent that many of jurists from near and far past-are devoted an independent treatise at their compilations. No-loss rule is essential from the past, even in the early days of Islam-for denial of essential provisions (horr Ameli, 1391). And respect the necessary actions are used by Shia scholars in different forms (Ansari, 1407).

This rule is one of the 4 or five general rules that many of Shia scholars are known that as the basis for creating jurisprudence; the term of this rule is based on the famous hadith of the Prophet "no hurt, no damage" that many of Shia and Sunni scholars are stated that in such way that many strong claims are stated about that; of course it is a situation that the other cause is presented for this rule especially The Holy Quran. There are many verses in the Quran that some of them explicitly and some others with interpretation and emphasis of negation and prevention of losses are implied. Not because of a dispute with the father's mother hit the child is right-and not his father.

And never because of hurt and damage, do not protect women. This holy verse denies men for keeping women in order to hurt them and do not divorce them.

Do not hurt those women who divorced from you in order to annoy them. This holy verse also forbids men to hitting infliction of divorced women in those days.

This holy verse has two translations. If "La Yozer" is read as active, its meaning is that to write and witness to right. And if "La Yozar" is read as passive, its meaning is that do not hurt others by books and witness. Set of the above verses are used that is hurt to non-lawful and illegitimate.

However, the main document of this rule is hadith of the Prophet "La Zarar La yozer" that is rhetoric miracle of Prophet Muhammad. Because of the multitude of-the hadith narrated this close to the frequency; because many friends of prophet has stated that some of them are AbbdollahEbn Abbas, AbouHarire, JaberEbneAbbdollah, Saeed Khadari, Abolbabe and ....(Nuri,1411)

Despite various discussions around this rule, this rule in each of the Five Religions is stated independently. Comparative study about it is very low. No doubly, comprehensive comparative studies and examining various viewpoints in one hand can make explicit ambiguity points and at the other hand it has provided an atmosphere 
from related scientific views with this issue. In other words, vast functions of this rule and significant effect of that at vast sections of legal issues and principles and ethics force us that more detailed studies do and we achieve a good result by counting Comments of different religionsscholars.

\section{Concept of Loss or No Loss}

Different meanings are stated for the term harm. It includes Bella and difficult-in the sense of scarcity and fear, illness and suffering in body-defects and deficiencies and ....it can be said that more various meaning are various signs of harm and harm is a religious meaning that is different in different times and locations. The definitions of Jurists also is close the religious meaning. But it drives those religious interpretations. Mr. Brojerdi has a comprehensive definition like above: "the term harm at religious concept, is the lack in property-honor or life of a guy or a dimension of private dimensions of guy, only if it can be applicable. In a way that religious consider its harm (Lankarani, 1383).

Martyr Sadr also defines the same and say, the hurt to life, honor or property is abstraction (Sadr, 1417).

EmamKhomeyni believes that hurt and hurts and their derivations, frequently are applied at live or financial issues- but the term "Zerar" most of time is used for difficulty, expanding, limitation and spiritual pressures (Sistani, 1414).

There are three theories for differences between "Zarar and Zerara":

1. Both of them are the same, but the only different is at infinitive form of them

2. Both of them are at the concept of common material and their difference is at single expression and specific expression.

3. Zarar and Zerar are different in nature

In the verses of the Holy Quran the term "Zerar" frequently is used at the surfer meaning and difficulty that masque building "Zerar" in front of "Ghva" masque, the goal of enemy was to limit Muslims(*tobe,107). At other verses the term (*baghare, 231) "Zerar" also used- that is referred to spiritual pressure and difficulty. At story of Samar EbneJondab the result of his action, at making that man sad was the same.

Regarding to the mentioned points "Zerar" are used at the following meaning:

1. Mutual Loss-because Zerar is subject that imply the mutual actions. Of course infinitives of subject are not always mutual. For example Safar, Hajara

2. Zarar and Zerar are synonym and have the same meaning.

3. Zerar means diffciculty and giving limitations. Some believe that Zerar is the repetition of Zarar

4. Zarar include deliberate loss or undeliberate loss. But Zerar exclusively is used at making deliberate losses. AllamaNaeeni believes that when Zarar and Zerar are used together. Zarar is referred to undeliberate loss and Zerar is referred to deliberate loss (Naieni, 1418). Late Maragheyi also known the term "Mozare" at the meaning of loss (Maraghi hoseini, 1417).

\section{Documents and Evidence of "La Zarar" Rule}

\subsection{Book}

It can be said that the entire instances of oppressions that are also the signs of loss. Generally, verses that talk about oppression and justice are also referred to removing loss. But some of the verses of the Holy Quran are referred clearly to term "Zarar" and its derivations that we explain some of them:

1.In the Holy Quran, an especial attention is given to family and denies the oppression regard women. Especially regarding to elements of time and place and different cultures, that trading women and kids were common there. The Holy Quran fought with this oppression and signified: do not keep women for hurt. One who does it, certainly he oppresses himself.

At the expression of Letadeto, being deliberate harm is clearly obvious.

2.At this Sura, other time denied parents to hurt their children because of problems of themselves. At divorcing husband and wife, children hurt especially child nursing juice. In this case, the Holy Quran stated: Parents must not hurt their children.

As it is clear, the Quran verses denied Zarar and Zerar and generally deny the truth is respected and we know it is not special case. In sum verses are presented rules for especial cases that referred to general description and proved La Zarar as a rule (Langaroodi, 1360 ). The rule that also have the wisdom emphasis because description 
of loss, at the level of law and performance, is not suitable for legislator and we know legislator at the legal system-at the words of Mr. Mozaffar and Isfahani, the owner of worse book of NahayelDeraye is the creator of wisdom (Mazaffar,1419).

\subsection{Tradition}

Narrated infallible, about denial loss, is a lot and are stated in different ways and with different expressions. These narratives sometimes refer to Zarar and Zerar and sometimes refer to derivations of Zarar without clearly refer to it. In other hand, these narratives are based on denial of loss and sometimes emphasize to removing harms that some of these verses are as follows:

1.At following narratives clearly stated about rules and denying it.

Zarar is the cause of wrong right for others (Of hurting anything by way of the Muslims, it is the guarantor of him) (Naraghi, 1410).

(Everything is detrimental to the path of the Muslims, its owner guarantor to fall ill) (Maraghi hoseini,1417).

(And spent the Messenger of Allah first refusal among partners in the earths and housing and said to LA ZARAR and LAZERAR) (horr Ameli,1403).

- From the Messenger of Allah (r): «The damage in the will, the growth of« The damages inWillfromElders » (Tabarsi,548,p.325)

\section{The following narrative is based on La Zarar}

Late Ameli, wrote«Inadmissibility of injustice in the will, and the injustice which exceeded one-third, and should be refunded to the Justice and known» «... from a neighbor in his will, received God Almighty, the Day of Resurrection, and it is the Exhibition»(Ameli,1403)

- Asked Abaabdallah (p) from the fortified weighed and is pregnant, he said, made even acknowledge what in her womb, and breastfeed her child, and then translated »(najafi,1362)

Regarding to explanations of hadith La Zarar as follow:

\section{La Zararva La Yozer}

\section{La Zararva La Yozer Fi Islam}

\section{La ZararVa La Zerar Ali Momen}

The statement of La Zararva La Yozer are the repeated narratives and are frequently occurred.

\subsection{Consensus}

However with wisdom reason, verses and narratives of infallible Imams, consensus, is documented consensus and independently does not have legal value. For that Martyr Bojnordi said that, the consensus of Islamic scholars is the explicit reason for rightness of this rule and is representor of the narrative of "La Zararva La Zerar", at narrative of Imam Ahmad EbneHanbal (hanbal,340) and other narrative books, the expression of "La ZararvaLaZerar"is stated.(bojnoordi,1413 )

\subsection{Reason}

In the opinion of some experts, denial loss-referred to the detriment of nature and reason-a negation of human independent and "independent wisdom" is referred to loss separate of religious rules. Their famous statement in this respect is: definite wisdom refer to Monem Sugar and certainly refers to denial loss.

Method and wisdom ways are not part of this verdict. Scientists blame those persons who hurt others without reason. These wisdom structures not only are emphasized by lawyer in one hand, but also are emphasized by scientists, regardless particular religion with nation and people.

\section{La Zarar Va La Zerar from the Perspective of Shia Scholars}

\subsection{The Viewpoint of Mr. Ansari (Denial Loss)}

Regarding to this viewpoint, the meaning of Hadith "La ZararVa La Zerar is that: from the lawyer perspective, each harmful verdict is removed, Both binding and nonbinding.

\section{Mr. Stated:}

After we could not get the real meaning of a sentence,the physical meaning of this sentence is that lawyer does not cheat verdict that harm to persons: not binding and nonbinding. It causes harm to guys. So regarding to this Hadith is removed and it harms the target person and dominant of owner is not possible without the license of 
exclusive man is removed (ansari,1419)

\subsection{Viewpoints of Fazel Toni}

Based on this viewpoint, the loss itself denied but not loss verdict but not each hurt but also un provided loss, in other words the interpretation of this Hadith is that there is no loss in Islam without compensate that and it refers that for each hurt, compensate is essentially and it refers to the necessity of removing harm for example the owner of restaurant says we do not have free food, so every person should pay money for his/her food.

Late Fazel Toni write in Vafiye book: since denial loss cannot have the truth meaning-because the truth loss is not removed, so the aim is that does not compensate in religion (toni,1059,p.194)

Mr. Ansari for complementing this theory says: if a loss is provided, from religion point of views no loss occurred.

For example: if a person be foolish, and sell his own property lower than its real price, he losses and his loss should be compensate.(khorasani,1406) Or is a rubber rubs a personal car and after he arrested he paid its cost, in religion perhaps there is no loss.

Late Ansari-know this viewpoint weak than other views and for rejecting it stated that: because it refers to necessity of compensate of loss, it cannot state for denial loss but when it can be said that loss is at external that loss really compensate or its cost paid. In other words, potential making is not correct, but current potential making is correct.(khorasani,1406)

\subsection{Mr. Isfahani}

Sheikh Shariyat believes that the meaning of the sentence of La ZararVa La Yozer is dinal loss and implies the task- it means that since drinking wine is unlawful -hurt to yourself and others is unlawful and does not refer to compensate of it.(sistani,1414)

He says if this sentence is free of any scientific doubt we can understand the same meaning, and then explain about current document that include:

1. The function of this combination at meaning of denying at Quran and current tradition:(There is no obscenity or immorality is no doubt in the Hajj); like Hajj is unlawful intercourse with women.

And also stated that Silence is unlawful and cheating in dealing is unlawful.

After bringing many cases of this combination he wrote: stating all narratives make the words too long and this is enough for those that deny this function from the rest sentences.(khorasani,1362)

2. As Mr. Ansari stated the second witness is the term "Amir Al Momenin" that at some narratives are fit with Null meaning.

3. The third witness as a great issue, the Holy Prophet said:Samareh you are harmless person and mar is unlawful task. But if we translate La Zarar as denial verdict, it will not be fit with first sentence.

\subsection{Viewpoints of Imam Khomeyni}

In viewpoint of Imam, the rule of La Zarar is denial-But not religious prohibition is to Sutra-but also governmental prohibitionhas been exported as leader and is careful about principle of monarchy and in fact it explains rules of monarchy at the meaning that at Islamic society, no one has right bother other by referring to rules of monarchy.

Holy Imam at explanation of his vote has stated several introductions.

First introduction

Suitable for Holy Prophet

Holy Prophet has three positions from God.

\section{A: Prophecy and Mission}

At this position the task of prophet is advertising religion verdict and getting the message of God to human.

\section{B: Governance}

At this position, the prophet is the leader of Islamic society and governing Islamic society is for him. Imam stated the different of these two positions:

At first position-prophet do not have any order from God-and if an order export from him has the guidance aspect to rules of God and defying that is the defying of God rules not rules of prophets. 
But at second position-Imam has stated order and his order is Molavi order not guidance obey of rules of him and defying them causes nearing to God.(Obey Allah and obey the Messenger and those of you). (nesa (4): 59.)

\section{Verdict}

One of the Imam tasks is arbitrate and resolve disputes between people and in this respect, God has stated his verdict necessary. (nesa (4): 65)

\section{Second introduction}

Criteria for knowing governmental narratives

Traditions have been narrated from the Prophet has different interpretations like: Ghala, Hokm, Amr-and refers to each narrative that starts with Hokm or Ghazi. It is clear that it is a governmental order-in this respect other interpretations are less seen, because they do not have governmental position and at a few cases, these interpretations are used that is not a governmental credit.

\section{Third introduction}

Governmental Verdicts with word Ghala

At some cases, some lawful issues are coming with term Ghala but there is a contrast. For example if at a hadith it is stated that prophet has said something to someone: you are the leader and go to that particular area, this is a governmental order, although it came with term Ghala or in a sentence by holy prophet, prophet said this property is for who that have reason.

Imam Khomeyni stated: perhaps it can be said that the term Amr is at the concept of governmental and term Ghazi is at the concept of Court order, but term Hokm does not exist in none of them-it can be either court order and is required for signifying each need.(khomeini,1378)

\section{Fourth introduction}

Moayedeh narrative

For emphasizing his word at second and third introduction-we examine set of narratives that are entered by mentioned words that includAbu Abdillah said: «The Messenger of Allah said, but spends between evidenceand faith»; (Colini.1365)

Holy prophet said I judge you by two witnesses.Imam after these preparations is concluded that the principle of this hadith is rejecting governmental rule and is part of prophet rules-either from view of Sunni or from point of view of Shia.(khomeini,1378)

Iman at the end says: if our point of views is better than other point of view at your opinion-so we say thank god-otherwise we put it as a mutual meaning as a probably.(khomeini,1378)

\section{Application of No Loss At Jurisprudence}

At different Juridical books-there are many cases that most famous of them is based on viewpoint at rule of La ZararVa La Zerar that they ordered based on it. And if a person search based on these books-he or she would get more cases.

First Martyr is his book of rule-persuade Foroee at this opinion and corporate it and Late (Makki ameli, 1091). Maragheyi also stated many branches of law is the rule. Even in cases of hardship together under this rule, and then a lot of these branches are listed notes (maraghi, 1417).

1. The necessity verdict of Ablution that most buy water in high price-is the essential verdict and based on that this rule should be removed.(tabatabayi,1417,vol.1,p.637)

2. The necessity of standing praying is has harm for human-is removed and can pray at sitting form.(tabatabayi,1196)

3. If doing some preparations of Haj has a high cost-the necessity of Haj is removed. (najafi,1362,vol.21,p.257)

4. One of the conditions of doing good deal and avoiding bad deal is no bothering and hurt other because of no loss rule.(najafi,1362)

5. If a husband became low and be absent and there was no news of him-and he did property for his wife, the leader after four years search for finding her husband can takes her divorce. MartyrSanni put the rules of divorce in his work as part of no loss rule.(makki amele,72,vol.6,p.65)

6. The hurt verdict, it complains in front of someone except that Imam is signified-this verdict is removed and it is lawful. 
7. One of laws that is proposed for transactions is the Khayar right. It means that two parties of transaction can void it without satisfaction of other. Khiyar right has different types. First Martyr mentions fourteen swore-but late Ansari at following of researcher, examines only seven swore. The necessity of doing so is that to remove cuse of loss to right person.

Khayar right of Fault: the customer can void the transaction or give something if he or she finds fault in target object.(najafi,1362)

Khayar right of cheating: if a person sell his property more than its real cost, if customer does not pay extra money-for sellers the right of Khayar is constant.

Many jurists rely La Zarar for proving right of Khayar (helli,1410) and Mr. ansari knows it as the strongest reason.

Delayed Khayar right: if customer does not pay the cost after three days, seller can void everything or can be tolerable. Mr. Halli stated that these issues are among Shiite scholars because patient of seller is loss.(helli,1410) Many other rules about marriage, divorce are stated.

\section{La ZararVa La Zerar from Sunni Perspective}

In Sunni jurisprudence, regardless the Quran verses that mentioned before-they examine the statement of La Zarar based on the Holy prophet view. High probability, the only document of Sunni is the narrative of EbadebneSamet.

\subsection{Abodolhanifeh Views}

According to Abdolhanifeh view, if a father get his daughter married with dowry of 18 dirhams and the social dignity of girl is 1000 dirhams, this marriage is true. Here Abolhanifeh put the basis based on the good intention of father but Abo Yousef and Mohammad Shaybani believe that this marriage is not true. According to their viewpoint, the right of the marriage of a girl that is given to father is not an absolute right, but also this right is given to him for protecting the benefits of their children. When a person get his daughter married with low dowry, this action hurt daughter, so this marriage is not true.

At reflection of La Zarar rule at contract tasks-Abohanifeh and his students said: if employers hire worker and then close up his work because of loss of customers, if can void his contract with worker, too. But if he changes the place of work, he cannot void his contract with his worker.

Hanafi jurisprudence study represents that the founders of this school believed that the criteria of no loss rule suppose know the intention of Ezrar especially those who hurt others by executing their own right-are responsible when they have intention of Ezrar.

\subsection{Malekebneanas Views}

Ask from Abolghasem that: Can father get their daughters married with low or high dowry with protecting their benefits? And Abolghasem answered: yes, this marriage is true. Because Malek said: Father has right to get married his daughter and also for protecting the daughter he can get married his daughter by lower or high dowry. (afandi,1323)

Here because father does not have a bad intention, his decision is true.

\subsection{Shafeyi Views}

From the important cases of applying rule of no loss is where a person execute his private right and at executing it do not hurt other. The story of Samare and many other verses and narratives of no loss rule is related to this assumption. Therefore- regarding the votes and Scholars fatwa is required. They are some cases that are representing Scholars views is the limit right of owner.

According to Shaafeyi point of view, those who take a property should return it as the first day. He can destroy whatever the owner has built and remove its sign. Meanwhile, usurping has right to cut the tree that he grown and make its place like a first day. As if the walls of house have beautiful things, he can remove them (shafei,1325)

According to Shafeyi view-the meaning of La Zararva La Zerar is that we cannot force other to take the property that is not for him and also we cannot ask someone to ignore his property. Mahmoud fathi said this Fatwa of Shaafeyirepresentd that he looked for for right.(fathi,1903)

From attention to various views from religion leaders of Sunni-it is clear that although in many cases that give attention to intention of Zerar but if it is said that the only criteria at La zarar rule that count the intention of 
Ezrar is difficult. But also it seems that a prominent point at other place and the point is that many of harms from others impose and they are under the title of misuse.

\section{Conclusion}

The no loss rule is one of the most famous and fundamental rules at Islamic law. The rule of justice in many cases develops from the rule of no loss. In other words, no loss rule is the way of developing justice-wisdom and equity. It also can be said that the main basis of this rule is justice and no loss is a tool for executing justice. And perhaps because of this, no loss rule has priority over other rules or it governs generality. The other basis of this government is religious orders and in fact corruption is the loss or loss is the corruption. According to this, each verdict that force to loss is a kind of corruption. In other words, description based on justice avoid from ugly things.

Famous scientists of jurisprudence like Mr. Taraghi-Mr. Ansari-Khorasani-Naeeni-Isfahani-Imam Khomeyni and others based on the law masters like Dr. Jafari and others have discussed about no loss rule and they present a deep point in this respect. This rule has prominent features that make it different with the rest of rules that some of these characteristics are:

1. No loss rule, because rule of justice is one of the factors for immortality of Islamic law of system. Explanation that harm and its various derivations is a common sense and changes at religion finally is a sign of hurt-and it processes the Islamic system with time and place they peace with demonstrations. And at the place of freedom of law-or at the words of Isfahani-in some cases like issue in religions, or at the words of late Naeeni and Mr. Sadr and at the area of free area there is a wide development. In palces with assist of rule of no loss justice, we can enter and answer the questions.

2. No loss rule like an alert guardian is standing with religious verdict in order to prevent oppression. The rule of no loss, is the principle of religion rules is rule. A spirit that tends to purposes of Sharriat-it put the middle and final purposes as a regard. Rules and religions provide a reasonable form. La zararva la zerar with the small misuse of owner of right and freedom edgy of individual in front of the benefits of others is signified. And this rule that the groups play is one of the honor of the legal system of Islam. The theory of misusing of right-perhaps more than one century is not existed at western law. But at Islamic jurisprudence even from holy prophet and by him-this rule was concerned to this wisdom order and opened the jurisprudence problems.

3. Regarding to mentioned explanations-it is clear that the rule of no loss-is the order rule. In term, it is order not right. In the term of lawyers is from the ordering rule not complementing rule. So agreement based on the loss is impossible-not only isn't satisfy for loss but the person does not let to force himself loss and not only satisfaction is not possible based on the loss but also the person does not have loss himself. This characteristic at the rest of other jurisprudence like Ghazar is prominent- it means that the transaction that is at risk and we cannot agree on it and pride dealing is unlawful. Late Halli says: when a party aware of a cheating, and he does not aware of the cost of transaction- the deal is unlawful.

4. No loss rule is based on the wisdom property and in somehow is part of natural law, too. Therefore what is expressed for emphasizing it at the words of Quran is only guidance and emphasis. According to this-Late Motehari stated: No loss refers to natural law. It means those who do not have right-he takes the other natural right like an oppression that force to that man.

So certain wisdom emphasizes the rule of no loss.

5. In discussion about rule of no loss and similar issues-on fact it is examination of jurisprudence issues or philosophy of law. Because these rules not only are the criteria for rate-but also they count as the principle of law. At principle or goals of this discussion: why disobeying the rules and also the discussion is that is the originality of individual or society or both? The security is the main purpose or justice? Or both? And all of these examinations are at the area of philosophy or law philosophy.

6. This rule is the key of efforts at times and places at different cultures. And effort at the words of Lahori is the dynamic motor of Islamic legal system. The rule of no loss is not only limit to financial and physical loss. But also it includes many moral meanings. In fact-this rule can force any hurt or property. They arrange the system with all the needs.

\section{Suggestions}

Our point of the view at meaning and principle of no loss is very different. Despite various discussions about rule of no loss in each one of Five religions independently is proposed. Therefore a comparative study is very low about it. No doubly comparative and comprehensive studies and examining various viewpoints can make 
explicit the ambiguity and complex rules and at the other hand is the suitable rest for using related scientific views. In other words, vast applications of this rule and prominent effect of that at different sections, a careful study occurs and counts the views of various religions to get an admirable result.

1. At the how of interpretation of principle of no loss-there are various theories. The rate of applicability of no loss rule is based on each of the current theories is different at its principle and they havehigh volatility. It seems that for removing this difference of view-the original principle of this rule should be reviewed and in somehow a new definition regarding to needs of modern life and current condition should be done. Because of these volatilities have no effects.

2. Each owner of right-should misuse the lawful rule. Misuse of right is a kind of bad way at executing of the right by others. Taking the right with one purpose and intention is accepted. Taking the right at executing the right action of self should have a good intention. A good intention is that right not given to others and at purposeful framework is done in a wrong way. Anyway-although the Scholars of Islam have various points of view- but the problem is that if it is the appointment the owner of right-having a good intention, so why we need rules? It seems that for making explicit of edge of owner of right-we should state the rules in the ground of jurisprudence.

3. Based on the rejecting the rules of no loss-the most applicability based on the view of rejecting governmental-has the less applicability. With these features-the different influence of each of them will be inapplicable and is ab obstacle of general community in this relationship. In fact approaching to this rule at a society-is the other life to the principle of that. Meanwhile, the existence of such content and principle and quality of executing the rule of no loss-can be an obstacle at influencing of that as a real religion law.

4. Some believed that all of the viewpoints and possibilities that are proposed for each principle of no loss rule-is possible. But at demonstrating dignity has rate. In other words-the mentioned point-has rate that if is existence it does not get to other level. With these descriptions-it seems for right understanding the distance of theory and practice should be clear.

5. The rule of no loss-if has differences-does not have function and at these cases regardless of the rule of La Zarar, he should refers other reason. Therefore, if for some reasons it should refers to other party, it is better that this rule use the lawful principle and get a new life.

\section{References}

Allah, K.-S. R. (1373). Al Resalo no loss rule. publishing institute of works of Imam.

Ameli-First Shahid-Mohammad Ebne Maki. (1362). Rule and principle:Mofid library.

Hassan, H.-M. (1391). Shia issues in education. Beyrot.

Hossein, B.-M. (1413). rules of jurisprudence. Qom- Ismaeelian institute.

Khomeyni, S. R. A. (1378). Beda Dor Fi Gheede La Zarar.

Khorasani-Ali. (1390). AlkaseboAlanvin Be Ehtemam Abodol Hossein Fayazi-publisher: Imam Hassan Ebne Ali.

Khorasani-Mohammad Kazem-Kafiyol Osol-Tehran-Islamiyeh library.

Kolini-Mohammad Bagher. (1375). Kafi Principle-Qom-Osve Publishing.

Maki-Ameli-ZeynolAbedin-Ebne Ali. (1418). Qom.

Maraghi-Hosseini-AbodolfataEbne Ali. (1383). titles-society publishing of Qom-office of Islamic.

Morteza, A.-S. (1410). Faraeedalasol-Beyrot- science institute.

Mozafar-Mahmoud. (1419). principle of jurisprudence-Beyrot.

Najafi-Mohammad Hassan. (1362). JavaherolKalam Fi Sharh-Qom.

Nouri-Tabasi-Mirza. (1411). second edition. Qom-Ahlebeyt Institute.

Sadr, S. (1417) science courses principle (Vol. 1). 45.

Sistani-Ali. (1414). Rule of no loss. Beyrot.

Tabarsi-AbiAllalFazlEbne Hassan. (1399). MajmaoAl Bayan-Qom-Farahani publishers.

TabatabeeYezdi-Seyed Mohammad Kazem-AroVasghi-Digital one. 


\section{Copyrights}

Copyright for this article is retained by the author(s), with first publication rights granted to the journal.

This is an open-access article distributed under the terms and conditions of the Creative Commons Attribution license (http://creativecommons.org/licenses/by/3.0/). 